\title{
ELEIÇÃO PARA DIRETORES E DIRETORAS DAS ESCOLAS MUNICIPAIS DE PONTA GROSSA - PARANÁ: ANÁLISE DA ESTRATÉGIA 19.2 DO PLANO MUNICIPAL DE EDUCAÇÃO
}

Kelly Letícia da Silva Sakata ${ }^{1}$ Elisângela Alves da Silva Scaff ${ }^{2}$

\section{RESUMO}

O presente texto objetiva analisar os processos de eleição de diretores e diretoras realizados no município de Ponta Grossa - PG no período de 2001 a 2017, com vistas a identificar as mudanças instauradas após a aprovação do Plano Municipal de Educação PME/PG (2015-2025). Especial destaque é dado à estratégia 19.2, que trata da nomeação de diretores e diretoras de acordo com critérios de mérito e participação. Para tanto, foi desenvolvida pesquisa documental, tendo como referência o Plano Nacional de Educação PNE (2014-2024), o Plano Municipal de Educação do município supracitado, bem como documentos oriundos do município após a aprovação do referido PME. A conclusão é que a estratégia 19.2 do PME/PG (2015-2025) efetivou-se no município em análise desde 2001, quando, em convênio com o Instituto Ayrton Senna, a Secretaria Municipal de Educação passou a exigir, dos candidatos à função de direção de escola, a frequência em um curso e submissão a processo avaliativo. Tal constatação leva a inquirir sobre o grau de influência desse Instituto, bem como de outras organizações do

1 Mestra em Educação pela Universidade Estadual do Centro Oeste (UNICENTRO). Doutoranda pelo Programa de Pós Graduação em Educação da Universidade Federal do Paraná (UFPR). Professora Colaboradora da Universidade Estadual do Centro - Oeste (UNICENTO/IRATI/PR). Integrante do Grupo de Pesquisa Estado, Política e Gestão em Educação e da Rede de Estudos e Pesquisas em Planejamento e Gestão Educacional (REPLAG). ORCID: http://orcid.org/0000-0003-41760412. E-mail: kelly.l.sakata@hotmail.com

2 Doutora em Educação pela Universidade de São Paulo (USP). Professora Associada da Universidade Federal do Paraná (UFPR). Integrante da Rede de Estudos e Pesquisas em Planejamento e Gestão Educacional (REPLAG) e do Núcleo de Políticas Educacionais (NUPE/ UFPR).ORCID: http://orcid.org/0000-0002-7682-0879. mail: elisscaff@gmail.com 
terceiro setor na definição de metas e estratégias dos planos educacionais no Brasil.

Palavras-chave: Planos de Educação. Gestão democrática. Política educacional.

\section{ELECTION FOR PRINCIPALS IN MUNICIPAL SCHOOLS OF PONTA GROSSA - PARANÁ: ANALYSIS OF THE STRATEGY 19.2 OF THE MUNICIPAL EDUCATION PLAN}

\section{ABSTRACT}

This work has as aim at analyzing the election processes for principals carried out in the municipality of Ponta Grossa - PG in the period from 2001 to 2017, in pursuance of identify changes established after the approval of the Municipal Education Plan - PME/PG (2015-2025). Special highlight is given to the strategy 19.2, which deals with the appointment of principals according to merit and participation criteria. Thereunto, a documental research was developed, based on the National Education Plan - NEP (2014-2024), the Municipal Education Plan of Ponta Grossa (PME - PG in Portuguese acronym), as well as documents from the municipality after the Municipal Education Plan already mentioned. The conclusion shows that the strategy 19.2 of the PME - PG (2015-2025) was effective in the municipality analyzed since 2001, when an agreement with Instituto Ayrton Senna and the Municipal Secretary of Education started to require attendance and assessment process from candidates to the principal position. Such findings lead to enquire on the influence degree of the Institute, as well as other organizations from the third sector on the definition of goals and strategies of educational plans in Brazil.

Keywords: Education Plan. Democratic management. Educational Policy. 


\section{ELECCIÓN PARA DIRECTORES Y DIRECTORAS DE LAS ESCUELAS MUNICIPALES DE PONTA GROSSA - PARANÁ: ANÁLISIS DE LA ESTRATEGIA 19.2 DEL PLAN MUNICIPAL DE EDUCACIÓN}

\section{RESUMEN}

Este trabajo tiene el objetivo de analizar los procesos de elección de directores y directoras realizados en el municipio de Ponta Grossa PG en el periodo de 2001 hasta 2017, para identificar los cambios instauradas después de la aprobación del Plan Municipal de Educación - PME/PG (2015-2025). Especial despegue se hace de la estrategia 19.2, que trata del nombramiento de directores y directoras de acuerdo con criterios de mérito y participación. Para ello, una investigación documental fue realizada, con referencia en el Plan Nacional de Educación - PNE (2014-2024), el Plan Municipal de Educación del municipio mencionado anteriormente, así como en documentos del municipio después de la aprobación del PME ya mencionado. La conclusión es que la estrategia 19.2 del PME/PG (2015-2025) se ha efectivado en el municipio analizado desde 2001, cuando un acuerdo entre el Instituto Ayrton Senna y la Secretaria Municipal de Educación empezó a exigir, de los candidatos a la función de dirección de escuela, frecuencia en un curso y sumisión a proceso evaluativo. Tal constatación lleva a preguntar sobre el grado de influencia de ese Instituto, así como de otras organizaciones del tercer sector en la definición de metas y estrategias de los planes educacionales en Brasil.

Palabras clave: Planes de Educación. Gestión democrática. Política educacional.

\section{INTRODUÇÃO}

Este artigo analisa os processos de eleição de diretores e diretoras realizados no município de Ponta Grossa (PG) no período de 2001 a 2017, com vistas a identificar as mudanças instauradas após a aprovação do Plano Municipal de Educação de Ponta Grossa, PR - 
PME/PG (2015-2025). Um destaque especial foi dado à estratégia 19.2 no desenvolvimento do trabalho, pois ela trata da nomeação de diretores e diretoras de acordo com critérios de mérito e desempenho.

O Plano Municipal de Educação de Ponta Grossa (PME/PG 2015-2025) define, em sua estratégia 19.2, "Garantir no prazo de dois anos de vigência deste PME que a nomeação dos diretores e diretoras de escolas municipais e Centros Municipais de Educação Infantil CMEls sigam critérios técnicos, bem como a participação da comunidade escolar" (PONTA GROSSA, 2015). Esta estratégia referese ao movimento de efetivação da meta 19 do Plano Nacional de Educação (PNE 2014-2024), no que diz respeito à gestão democrática:

Assegurar condições, no prazo de 2 (dois) anos, para a efetivação da gestão democrática da educação, associada a critérios técnicos de mérito e desempenho e à consulta pública à comunidade escolar, no âmbito das escolas públicas, prevendo recursos e apoio técnico da União para tanto (BRASIL, 2014).

A referente meta está em consonância com os princípios estabelecidos pela Constituição Federal, art. 205, VI, e pela Lei de Diretrizes e Bases da Educação, art. $3^{\circ}$, VIII e art. 14, a qual aponta o princípio da gestão democrática na esfera da educação pública. Todavia, implica um prazo de dois anos para sua efetivação em todo o país, até junho de 2016, conceituando a dita meta com a "definição de critérios que associem mérito e participação" (SOUZA, 2018, p. 69).

Considerando a necessidade de alinhamento dos planos estaduais e municipais de educação estabelecida no PNE (20142024), bem como a adequação do PME-PG (2015-2025), de forma a atender ao estabelecido no PNE supracitado, emerge a problemática central deste estudo: Há um alinhamento entre o PME-PG (20152025) e o PNE (2014-2024) no que se refere à meta 19 ? O que muda na forma de escolha dos dirigentes escolares após o PNE (2014-2024) e o PME/PG (2015-2025)? Quais ações foram desenvolvidas no âmbito educacional municipal de Ponta Grossa - PR para que a estratégia 19.2 do PME/PG (2015-2025) fosse efetivada? 
Para concretizar a análise, uma pesquisa documental foi desenvolvida, com a utilização de decretos oriundos do município de Ponta Grossa e relatórios do $1^{\circ}$ e do $2^{\circ}$ ciclo de monitoramento das metas do PNE (2014-2024), para além do PNE (2014-2024) e do PME/PG (2015-2025).

$\mathrm{Na}$ primeira seção do texto em tela, foram analisados os aspectos históricos mais relevantes em relação à emergência dos Planos Nacionais de Educação no Brasil. Em seguida, a meta 19 do PNE (2014-2024) foi problematizada, discorrendo sobre o conceito de gestão democrática, o monitoramento realizado e as ferramentas para avaliação desta meta. Ao final, apresenta-se uma análise específica sobre a estratégia 19.2 do município de Ponta Grossa - PR.

\section{OS PLANOS NACIONAIS DE EDUCAÇÃO NO BRASIL:}

Fragilidades

A trajetória de elaboração dos planos nacionais de educação no Brasil foi marcada por duros embates, especialmente advindos do contexto político e econômico de cada momento histórico. Sob este prisma, a ideia de um PNE emergiu por meio do Manifesto dos Pioneiros da Educação Nova ${ }^{3}$, em 1932. Logo após, os pioneiros realizarem o diagnóstico da educação pública no Brasil e indicarem suas finalidades (BRASIL, 2014; SAVIANI, 2014; SCAFF, OLIVEIRA, LIMA, 2018). Todavia, o documento denominado Plano de Educação Nacional "[...] não chegou a ser aprovado e, com o advento do Estado Novo em novembro de 1937, caiu no esquecimento" (SAVIANI, 2014, p. 76).

O ideário de planejamento educacional ressurgiu em 1945, no bojo da abertura democrática, culminando com a proposta de PNE encaminhada pelo Conselho Federal de Educação ao Ministro da Educação, em 1962. Tal proposta, no entanto, não chegou a ser aprovada, considerando o turbulento cenário político nacional que

\footnotetext{
3 Refere-se a um documento escrito por 26 educadores, em 1932, com o título $A$ reconstrução educacional no Brasil: ao povo e ao governo. Circulou em âmbito nacional com a finalidade de oferecer diretrizes para uma política de educação (MENEZES; SANTOS, 2001).
} 
resultou no golpe civil-militar de 1964. O período ditatorial instaurado desde então concentrou o planejamento nas "mãos da tecnocracia", e retira-se a "vinculação constitucional do financiamento da educação pelo executivo federal" (SCAFF; OLIVEIRA; LIMA, 2018, p. 919).

Somente na década de 1980 a reabertura democrática brasileira reacendeu a discussão sobre o planejamento educacional, resultando na aprovação do primeiro PNE (2001-2011), por meio da Lei $n^{\circ} 10.172$ de 2001 (BRASIL, 2001). Todavia, a Lei de Diretrizes e Bases da Educação Nacional, LDB 9394/1996, ao estabelecer a exigência de elaboração do $\mathrm{PNE}$, em articulação com os entes federados, não incluiu, entre os partícipes, membros da sociedade civil (BRASIL, 1996).

Dessa forma, a tramitação do PNE (2001-2011) ocorreu mediante o embate entre dois projetos. Como analisam Scaff e Oliveira (2018, p. 143), um deles foi coordenado pelo Fórum Nacional em Defesa da Escola Pública (FNDEP), com ampla "participação da sociedade brasileira, por meio de dois Congressos Nacionais de Educação (CONED) ${ }^{4}$, e outro articulado pelo governo federal.

Resultou desse processo um plano considerado frágil, tanto pela forma como foi organizado, quanto pela falta de recursos financeiros para assegurar sua viabilidade (SAVIANI, 2014; SCAFF; OLIVEIRA, 2018). Embora houvesse diagnóstico e um grande número de metas, o veto por parte do presidente Fernando Henrique Cardoso, da meta que determinava o investimento público em educação de $7 \%$ do PIB, jogou por terra qualquer possibilidade de sua implementação, como analisa Pinto (2014).

Destaca-se, ainda, a pouca atenção dos governos que se seguiram, no que tange as ações que necessitariam ser

${ }^{4}$ Os anos 1990 e a primeira década dos anos 2000 são marcados pela realização dos Congressos Nacionais de Educação - Coned, organizados por diversas entidades representativas do campo educacional, cujos temas abordaram o planejamento da educação nacional, direta ou indiretamente, no intuito de elaborar o PNE: I Coned, Belo Horizonte, 1996; II Coned, Belo Horizonte, 1997; III Coned, Porto Alegre, 1999; IV Coned, São Paulo, 2003; e V Coned, Recife, 2004. A segunda década dos anos 2000 até o momento é marcada pela realização de duas Conferências Nacionais de Educação, denominadas Conae, respectivamente em 2010 e 2014 (LAGARES; ALMEIDA; SANTOS, 2018). 
desencadeadas para o atingimento das metas. A Lei que instituiu 0 PNE (2001-2011) determinou, no seu artigo $2^{\circ}$ e $3^{\circ}$ :

Art. 2 A partir da vigência desta Lei, os Estados, o Distrito Federal e os Municípios deverão, com base no Plano Nacional de Educação, elaborar planos decenais correspondentes. Art. 3으 Anião, em articulação com os Estados, o Distrito Federal, os municípios e a sociedade civil, procederá a avaliações periódicas da implementação do Plano Nacional de Educação (BRASIL, 2001).

Para cumpri-la, de acordo com Ferreira e Fonseca (2011), o Ministério da Educação - MEC deveria ter desenvolvido uma estrutura capaz de atender essas indicações. No entanto, somente em dezembro de 2005 designou uma gerência denominada Programa de Acompanhamento e Avaliação do PNE e dos Planos Decenais Correspondentes, que realizou três seminários para a formação de técnicos e gestores das secretarias estaduais e municipais de educação. Portanto,

[...] no momento de expirar a vigência do PNE muitas de suas metas não foram alcançadas no âmbito da administração federal e dos governos estaduais e municipais e praticamente a metade dos municípios brasileiros conta com plano municipal de educação, o que atesta as críticas sobre o descumprimento do plano (FERREIRA; FONSECA, 2011, p. 77).

Considerado um plano pouco efetivo no sentido de consolidar uma política para a educação nacional, o PNE (2001-2011) foi substituído pelo atual PNE (2014-2024), aprovado pela Lei $n$. 13.005, de 25 de junho de 2014 (BRASIL, 2014). Foi elaborado a partir da mobilização da sociedade civil brasileira, por meio da Conferência Nacional de Educação (CONAE-2010), coordenada pelo governo federal e marcada por tensões de ordem política e econômica. Assim, o PNE (2014-2024) emergiu por meio de

[...] amplo debate ocorrido nas diversas etapas da Conferência Nacional de Educação (CONAE) nos 
anos de 2010 e 2014. Composto por diretrizes, metas e estratégias que abrangem todos os níveis, etapas e modalidades de ensino, o PNE visa ampliar o acesso e a melhoria da qualidade da educação nacional com vistas a garantir os direitos constitucionalmente consagrados (SCAFF; OLIVEIRA, 2018, p. 144).

Para além do processo de elaboração, o PNE (2014-2024) se diferencia do PNE (2001-2011) também pela sua estrutura, pois apresenta apenas 20 metas, quando o plano anterior se desdobrava em 295. Todavia, esta diferença é considera aparente por Saviani (2014), considerando que as 20 metas se desdobram em 170 estratégias, entendidas como submetas específicas.

Para além das estruturas diferentes, Saviani (2014) destaca a falta de diagnóstico, elemento de suma importância para o alcance das metas. "Isso porque o diagnóstico, enquanto caracterização da situação com seus limites e carências, fornece a base e a justificativa para o enunciado das metas que compõem o plano a ser executado" (SAVIANI, 2014, p. 84). Neste sentido, para o autor, o plano torna-se frágil.

Concordando com o autor supracitado, Sabia e Alaniz (2015, p. 46) apontam que, além

[...] da falta do diagnóstico, o PNE atual não traduz o conjunto das deliberações aprovadas pela Conferência Nacional de Educação (Conae/2010) [...], mas representou novamente um esforço coletivo dos educadores para deliberar um documento final que expressasse a educação brasileira que a sociedade deseja.

Em análise sobre o sentido de gestão democrática, especificamente a meta 19, Lino e Morgan (2018) indicam que o PNE (2014-2024) não incorporou as expectativas da sociedade manifestadas na CONAE, uma vez que contraria bastante os sentidos expostos e analisados na conferência. Tais sentidos foram construídos historicamente no âmbito das disputas no campo do planejamento educacional brasileiro, a exemplo da Conferência Nacional de Educação para Todos (1994) e das CONED (SOUZA, 2016). Essas 
disputas permanecem no cenário da política educacional brasileira, manifestando-se no PNE aprovado em 2014.

Como consequência da aprovação do atual plano, os estados e municípios foram instados a elaborar e aprovar seus respectivos planos com metas articuladas às metas nacionais. De acordo com o Artigo $5^{\circ}$ do plano, as instâncias responsáveis pelo monitoramento contínuo e avaliações periódicas são: o Ministério da Educação (MEC); a Comissão de Educação da Câmara dos Deputados e Comissão de Educação, Cultura e Esporte do Senado Federal; o Conselho Nacional de Educação (CNE); e o Fórum Nacional de Educação (FNE). O parágrafo $2^{\circ}$ do mesmo Artigo $5^{\circ}$ atribuiu, ao Inep, a responsabilidade de publicar estudos para aferir a evolução no cumprimento das metas estabelecidas a cada 2 (dois) anos (BRASIL, 2014).

Para o desenvolvimento dos planos em âmbito Nacional, estaduais, municipais e do Distrito Federal, o MEC organizou o site denominado Planejando a Próxima Década, com orientações para a elaboração dos planos. $O$ trabalho foi realizado com a contribuição do Conselho Nacional de Secretários de Educação (Consed), da União Nacional dos Dirigentes Municipais de Educação (Undime), da União Nacional dos Conselhos Municipais de Educação (UNCME), do Fórum Nacional de Conselhos Estaduais de Educação (FNCE) e do Conselho Nacional de Educação (CNE) (BRASIL, 2019).

Esse movimento de elaboração dos planos estaduais e municipais "[...] traz à cena o debate acerca do planejamento educacional, apontando avanços, limites e desafios a serem enfrentados pelos 26 estados, Distrito Federal e 5.570 municípios" (SCAFF; FONSECA, 2016, p. 15). Neste sentido, na próxima seção, tratamos da elaboração e monitoramento da meta 19 do PNE (20142024), referente à gestão democrática, no planejamento do município de Ponta Grossa (PR).

\section{GESTÃO DEMOCRÁTICA NO PNE (2014-2024): Meta 19}

Especificamente em relação à meta 19 do PNE (2014-2024), que trata de assegurar as condições para a efetivação da gestão 
democrática no prazo de 2 anos, merecem destaque as estratégias relacionadas ao provimento dos diretores e diretoras.

\begin{abstract}
Estratégias:
19.1. Priorizar o repasse de transferências voluntárias da União na área da educação para os entes federados que tenham aprovado legislação específica que regulamente a matéria na área de sua abrangência, respeitando-se a legislação nacional, e que considere, conjuntamente, para a nomeação dos diretores e diretoras de escola, critérios técnicos de mérito e desempenho, bem como a participação da comunidade escolar;

[...]

19.8. Desenvolver programas de formação de diretores e gestores escolares, bem como aplicar prova nacional específica, a fim de subsidiar a definição de critérios objetivos para o provimento dos cargos, cujos resultados possam ser utilizados por adesão (BRASIL, 2014, grifo nosso).
\end{abstract}

De acordo com a problemática contemplada no presente artigo, a pesquisa ateve-se ao levantamento de dados referentes ao provimento de diretores e diretoras. Neste levantamento foram selecionados os seguintes documentos: Relatório do $1^{\circ}$ ciclo de monitoramento das metas do PNE: Biênio 2014-2016 (BRASIL, 2016); Relatório do $2^{\circ}$ ciclo de monitoramento das metas do Plano Nacional de Educação - 2018 (BRASIL, 2019); e o Relatório final, intitulado Estudo sobre forma de disponibilização de dados e indicadores municipais para monitoramento e avaliação dos planos municipais de educação 2015/2025 (BRASIL, 2018).

O Relatório do $1^{\circ}$ ciclo de monitoramento das metas do PNE: Biênio 2014-2016 apresenta 4 indicadores para a meta 19: o 19A percentual de diretores de escolas públicas que foram escolhidos para a ocupação do cargo por meio de critérios técnicos de mérito e desempenho e de consulta pública à comunidade escolar; o 19B percentual de escolas públicas que contaram com a participação de profissionais da educação, pais e alunos na formulação dos projetos político-pedagógicos e na constituição do conselho escolar; o 19C percentual de escolas públicas que recebem recursos financeiros dos 
entes federados; e o 19D - condições em que os diretores exercem o cargo (BRASIL, 2016).

Já o Relatório do $2^{\circ}$ ciclo de monitoramento das metas do Plano Nacional de Educação - 2018 apresenta 2 indicadores: 19A - o percentual de unidades federativas que selecionam diretores de escolas públicas da rede de ensino estadual por meio de eleições e critérios técnicos de mérito e desempenho; e 19B - o percentual de municípios que selecionam diretores de escolas públicas da rede de ensino municipal por meio de eleições e critérios técnicos de mérito e desempenho (BRASIL, 2019).

Observa-se, assim, que os indicadores se modificaram do primeiro para o segundo ciclo de monitoramento do PNE, atendo-se somente à seleção de diretores e diretoras como forma de monitoramento da meta 19. O Relatório final, intitulado Estudo sobre a forma de disponibilização de dados e indicadores municipais para monitoramento e avaliação dos planos municipais de educação 2015/2025, indica como fator limitador para a obtenção de informações, quanto aos dados que compõem esses indicadores para o conjunto de municípios, a ausência da divulgação de dados relacionados ao indicador. Este fato ocorre, pois não há publicação dessas informações de forma consolidada (BRASIL, 2018).

No Relatório do $7^{\circ}$ ciclo de monitoramento das metas do PNE: Biênio 2014-2016, os dados mostram diferentes processos adotados pelos entes federados para a ocupação do cargo de diretor escolar, prevalecendo a escolha por indicação, em que se sobressai o ente federativo municipal, com $59 \%$. O processo misto de seleção e eleição para a ocupação do cargo de direção escolar só era adotado por 12,2\% dos estabelecimentos de ensino em 2013 (BRASIL, 2016).

Observa-se que, em 2013, a rede federal apresentava 3,9\% das escolas utilizando o processo misto de seleção e eleição; as redes estaduais, 21,6\%; e as redes municipais, $6,6 \%$. Conclui-se, de acordo com o referido relatório, que a escolha de diretores escolares ocorre de diferentes formas e envolve procedimentos diversos, predominando, em 2013, aqueles relacionados a algum tipo de indicação. Ainda, que o processo misto de seleção e eleição ocorre em apenas $12,2 \%$ das escolas, estando mais centralizado nas redes estaduais e nas localidades urbanas. 
No Relatório do $2^{\circ}$ ciclo de monitoramento das metas do Plano Nacional de Educação - 2018, constata-se que os resultados do indicador 19A são: a. 70\% das unidades federativas (18 estados e o DF) realizam eleições e estabelecem critérios técnicos de mérito e desempenho na escolha de diretores das escolas estaduais; b. $85 \%$ das unidades da Federação (22 estados e o Distrito Federal) realizam eleições como uma das etapas do processo de escolha de diretor das escolas da rede estadual de ensino; c. Sete estados possuem mecanismos de avaliação do mandato do diretor eleito durante a sua gestão; e d. Em 20 estados e no Distrito Federal é permitida a reeleição de diretores das escolas da rede de ensino estadual.

Em relação aos resultados do indicador 19B, tem-se: a. 6\% dos municípios realizam eleições e estabelecem critérios de mérito e desempenho na escolha dos diretores das escolas municipais; $b$. $16,6 \%$ dos municípios realizam eleições como uma das etapas de seleção de diretores das redes municipais; c. Há indicação de diretores das escolas públicas das redes municipais em $74 \%$ dos municípios; e d. A eleição como forma de seleção de gestores das escolas municipais apresenta os maiores percentuais de frequência entre municípios com mais de 100 mil habitantes.

Os dados apresentados pelos relatórios em análise indicam que os estados e o Distrito Federal têm avançado mais em direção ao cumprimento da meta 19. A realidade municipal, de maneira geral, está longe de alcançar a meta proposta, considerando a predominância das indicações aos cargos de diretores e diretoras escolares, que passa, de $59 \%$ das escolas no Relatório do $1^{\circ}$ ciclo, para $74 \%$ no Relatório do $2^{\circ}$ ciclo de monitoramento das metas do Plano Nacional de Educação - 2018.

\section{ELEIÇÃO DE DIRETORES E DIRETORAS NO MUNICíPIO DE PONTA GROSSA: Estratégia 19.2}

A forma de provimento de diretores e diretoras é um tema polêmico que se revela desafiador, na medida em que a literatura especializada na área aponta diferentes posicionamentos. No entanto, o movimento de escolha por meio da eleição, de forma 
geral, tem sido associado a mecanismos de gestão democrática da educação, princípio garantido na Constituição Federal de 1988, que visa a oportunizar a participação dos envolvidos e da comunidade na escolha dos dirigentes escolares. Sob este prisma, nas duas últimas décadas,

[...] a realização de eleições como prática para definir o candidato a ocupar a função de diretor de escola, permitiu a realização de uma série de experiências, visando a qualidade nos serviços prestados à população. É evidente que apenas a realização de eleições não garante o processo de gestão das escolas com qualidade. Portanto, vários dispositivos foram criados visando definir os critérios que melhor atenderiam o determinado pela legislação, pautada pelos resultados obtidos no cotidiano das unidades escolares e que se referem ao perfil exigido (experiência e formação), ao período de gestão (incluindo o dispositivo da reeleição), realização de cursos e provas, apresentação de plano de trabalho, eleição propriamente dita, dentre outros (LUPORINI; MARTINIAK; MAROCHI, 2011, p. 215).

O Estado do Paraná, neste panorama, foi um dos primeiros que adotou a prática das eleições, especificamente no município de Ponta Grossa. Segundo Mello (2014), a primeira eleição para diretores ocorreu em 1986, regulamentada por meio do Decreto $n^{\circ} 439 / 86$, sendo o período de mandato de dois anos. Poderiam votar os professores, os integrantes da equipe administrativa e serventes lotados no estabelecimento, podendo ser votados os professores pertencentes ao estabelecimento.

O mandato do diretor foi modificado para quatro anos pelo Decreto $n^{\circ} 681 / 2001$, o qual indicava que poderiam se candidatar os professores integrantes do quadro próprio do magistério público municipal que possuíssem curso superior na área da Educação, ou estivessem cursando, e que não tivessem recebido penalidade. Poderiam votar: os professores; os integrantes da equipe técnicoadministrativa e de apoio lotados no estabelecimento; os membros titulares da Associação de Pais e Mestres - APM; os pais ou 
responsáveis por alunos menores de dezesseis anos e os alunos com idade com igual ou superior a dezesseis anos. O voto dos pais e dos alunos deveria representar, no mínimo, 60\% de participação desse segmento (PONTA GROSSA, 2001).

Os estudos de Mello $(2014 ; 2015)$ indicam que, para além dos itens ressaltados no decreto supracitado, os candidatos teriam que participar de um curso de gestão escolar, coordenado pela Secretaria Municipal de Educação (SME), com duração de vinte horas e assiduidade de $100 \%$, submetendo-se a processo avaliativo referente ao referido curso, com aproveitamento de $70 \%$. Tais critérios, embora não apareçam no Decreto $n^{\circ} 681 / 2001$, são identificados nas pesquisas desenvolvidas por Mello (2014; 2015).

Também a partir de 2001, a SME de Ponta Grossa assinou convênio com o Instituto Ayrton Senna (IAS), aderindo ao Programa Gestão Nota 10. Em uma busca específica sobre essas orientações, no que se refere ao PNE e o PME-PG, o Relatório de 2012 do IAS indica que "o programa Gestão Nota 10 oferece capacitação e ferramentas gerenciais aos diretores de escola e equipes de secretaria de educação. Trabalha com indicadores e estabelece metas a serem cumpridas" (INSTITUTO AYRTON SENNA, 2012, p. 01), não especificando quais seriam estas metas.

Adrião e Peroni (2011, p. 48) esclarecem que "o programa Gestão Nota 10 foi adotado como política pública, a partir de convênios firmados por 35 municípios em 22 estados da Federação". Segundo as autoras, todos esses municípios introduziram alterações nos critérios adotados para a escolha dos dirigentes escolares, processo que descaracterizou os princípios de gestão democrática, mesmo naqueles municípios que realizavam eleições para diretor ou diretora. Isto porque o diretor eleito era obrigado a assumir um termo de compromisso previamente definido, em alguns casos, sofrendo sanções se não cumprisse as metas estabelecidas.

Em 2005, o Decreto no 590 do município de Ponta Grossa estabeleceu que poderia se candidatar a diretor ou diretora aquele que obtivesse aproveitamento de $80 \%$ no curso, desde que tivesse $100 \%$ de assiduidade. Acrescentou, ainda, a necessidade de apresentação de um memorial e o plano de ação a ser desenvolvido em seu mandato, que passariam pela avaliação da SME. Ao final do 
processo, ocorreria a consulta à comunidade através do voto, sendo considerada válida a eleição que tivesse a participação de $50 \%$ mais um dos representantes. Para além disto, cada família teria um representante para votar, podendo ser responsáveis ou familiares, que deveria se inscrever como votante para participar no dia da eleição (PONTA GROSSA, 2005).

Em 2008, a Lei no 9835 aprovou o Plano Municipal de Educação - PME-PG (2008-2018). Nesta lei não houve meta específica sobre gestão democrática. Indica o lançamento da coleção Desatando nós: desafios e inovações nas práticas gestoras das diretoras das unidades escolares como decorrência do Prêmio Inovação em Gestão Educacional, concedido ao município de Ponta Grossa pelo MEC e Inep, pela excelência demonstrada na gestão da Secretaria Municipal de Educação referente ao provimento de gestores de 2005 (PONTA GROSSA, 2008).

Em 2015, por meio da Lei $n^{\circ} 12.213$, instituiu-se o Plano Municipal de Educação - PME-PG (2015-2025). A meta 19 consiste na transcrição da meta 19 do PNE (2014-2024), e sua estratégia 19.2, objeto da presente pesquisa, visa a "garantir no prazo de dois anos de vigência deste PME que a nomeação dos diretores e diretoras de escolas municipais e CMEls sigam critérios técnicos, bem como a participação da comunidade escolar" (PONTA GROSSA, 2015).

Entende-se que essa estratégia está em consonância com a estratégia 19.1 do PNE (2014-2024), a qual indica:

19.1) priorizar o repasse de transferências voluntárias da União na área da educação para os entes federados que tenham aprovado legislação específica que regulamente a matéria na área de sua abrangência, respeitando-se a legislação nacional, e que considere, conjuntamente, para a nomeação dos diretores de escola, critérios técnicos de mérito e desempenho e participação da comunidade escolar (BRASIL, 2014).

Assim, após a aprovação do referido plano, o Decreto $n^{\circ}$ 13.506 de 2017 acrescentou as seguintes mudanças em relação à eleição de diretores e diretoras: a assiduidade no curso para gestores mudou de $100 \%$ para o mínimo de $90 \%$; e o aproveitamento, de $80 \%$ 
para, no mínimo, 70\%. Estar no estágio probatório passou a constituir impeditivo para a candidatura, salvo se o candidato possuir, no mínimo, 05 anos de experiência comprovada na Educação Infantil e/ou Ensino Fundamental - Anos Iniciais ( $1^{\circ}$ ao $5^{\circ}$ ano), e possuir curso de Licenciatura Plena em Pedagogia. O Decreto anterior permitia que concorressem candidatos com curso de Licenciatura e pós-graduação em nível stricto sensu na área da educação (PONTA GROSSA, 2017).

Constata-se, portanto, que embora a eleição de diretores esteja estabelecida desde 1986, os critérios técnicos de mérito e desempenho, aliados à consulta pública à comunidade escolar, foram inseridos somente em 2001, ano em que a SME firmou convênio com o Instituto Ayrton Senna, aderindo ao Programa Gestão Nota 10. Observa-se, assim, que o alinhamento ao $P N E$, no que se refere à meta 19, nada acrescentou ao PME-PG, uma vez que tais critérios já haviam sido incorporados sob a indução de tal instituto, no início da década.

Tais constatações fazem emergir os seguintes questionamentos: Tendo como referência o conceito de plano como "uma atividade humana presente no cotidiano de todos os indivíduos, pela qual estes estabelecem objetivos a serem atingidos e formulam as estratégias de ação para alcançá-los" (SCAFF, 2007, p. 42), por que essa estratégia foi elaborada, se já havia sido efetivada 14 anos antes da proposição do PME/PG (2015-2025)? Por que não foi realizado um diagnóstico acerca da meta 19, para adequar a estratégia 19.2? Qual a influência do Instituto Ayrton Senna na elaboração e no monitoramento da meta 19 do PME/PG?

$\mathrm{Na}$ busca de respostas a essas questões, foi realizado um levantamento na página eletrônica do município de Ponta Grossa e nos Relatórios de Avaliação e Monitoramento dos Planos Municipais de Educação (BRASIL, 2019). Porém, não foi encontrado nenhum documento referente ao acompanhamento da meta 19 no município em análise. 


\section{CONCLUSÃO}

Este artigo almejou problematizar as ações que foram desenvolvidas no âmbito educacional municipal de Ponta Grossa PR, para que a estratégia 19.2 do PME/PG (2015-2025) fosse efetivada. A partir das análises propostas, conclui-se que a estratégia 19.2 do plano supracitado foi efetivada pelo município quatorze anos antes de sua proposição, desde que o município aderiu ao Programa Escola Nota 10, do Instituto Ayrton Senna.

As normativas editadas após 2001, sobre a eleição de diretores, apresentam arranjos pontuais em relação à formação, realização de curso e avaliação destinados ao futuro candidato ao cargo de direção de escola. Inclui-se em tais arranjos o Plano Municipal de Educação de Ponta Grossa (PME-PG) que, ao estabelecer seu alinhamento com o PNE (2014-2024), não deixa de atender à prerrogativa estabelecida em 2001, sob a indução do Instituto Ayrton Senna. Isto leva a inquirir sobre o grau de influência desse Instituto e/ou outras organizações do Terceiro Setor ${ }^{5}$, na definição das metas e estratégias do PNE (2014-2024). Isto porque, como afirmaram Lino e Morgan (2018), o sentido de gestão democrática, precipuamente a meta 19, não incorporou as expectativas da sociedade manifestadas na CONAE.

Tais constatações acenam para a complexidade do processo de elaboração de políticas, manifestada na correlação de forças entre grupos sociais de interesses diversos que, por vezes, se apropriam de um discurso progressista com vistas a resguardar valores altamente conservadores defendidos no âmbito da transferência da lógica empresarial para a educação pública.

\section{REFERÊNCIAS}

ADRIÃO, T.; PERONI, V. Consequências da atuação do Instituto Ayrton Senna para a Gestão da educação pública: observações

\footnotetext{
${ }^{5}$ Entende-se o Terceiro Setor como sociedade civil organizada não estatal, empresas que não visam lucro e são conhecidas como Organizações não governamentais. Em outras palavras, Fundações, Institutos ou Associações sem fins lucrativos.
} 
sobre 10 estudos de caso. Práxis Educativa, Ponta Grossa, v.6, n.1, p. 45-53, jan.-jun. 2011. Disponível em:

https://www.revistas2.uepg.br/index.php/praxiseducativa/article/do wnload/2522/1998/. Acesso em: 10 jan. 2020.

BRASIL. Instituto Nacional de Estudos e Pesquisas Educacionais Anísio Teixeira. Relatório do $\mathbf{1}^{\circ}$ Ciclo de Monitoramento das

Metas do Plano Nacional de Educação: biênio 2014-2016. Brasília, DF: Inep, 2016. Disponível em: http://portal.inep.gov.br/informacaoda-publicacao/-

/asset_publisher/6JYIsGMAMkW1/document/id/626732. Acesso em: 12 dez. 2019.

BRASIL. Instituto Nacional de Estudos e Pesquisas Educacionais Anísio Teixeira. Relatório do $\mathbf{2}^{\circ}$ Ciclo de Monitoramento das Metas do Plano Nacional de Educação - 2018, 2. ed. Brasília, DF: Inep, 2019. Disponível em: http://portal.inep.gov.br/informacao-dapublicacao/-

/asset_publisher/6JYlsGMAMkW1/document/id/6725829. Acesso em: 11 dez. 2019.

BRASIL. Lei no 10.172, de 9 de janeiro de 2001. Institui o Plano Nacional de Educação e dá outras providências. Diário Oficial da União, Brasília, DF, 10 jan. 2001. Disponível em:

http://www.planalto.gov.br/ccivil_03/leis/leis_2001//10172.htm. Acesso em: 15 jan. 2020.

BRASIL. Lei no 13.005, de 25 de junho de 2014, que aprova o Plano Nacional de Educação (PNE) e dá outras providências. Brasília:

Câmara dos Deputados, Edições Câmara, 2014. Disponível em:

http://bd.camara.leg.br/bd/bitstream/handle/bdcamara/20204/plan o_nacional_educacao_2014-2024_2ed.pdf?sequence=13 Acesso em: 15 jan. 2020.

BRASIL. Lei no 9.394, de 20 de dezembro de 1996. Estabelece as diretrizes e bases da educação nacional. Diário Oficial da União, Brasília, DF, 23 dez. 1996. Disponível em: http://www.planalto.gov.br/ccivil_03/leis/19394.htm. Acesso em: 10 jan. 2020. 
BRASIL. Ministério da Educação. Plano Nacional de Educação em Movimento. Monitoramento e Avaliação dos Planos Subnacionais de Educação. Relatório final: Estudo sobre forma de disponibilização de dados e indicadores municipais para monitoramento e avaliação dos planos municipais de educação 2015/2025. Paraná, 2018. Disponível em:

http://pne.mec.gov.br/publicacoes/itemlist/category/4monitoramento-e-avaliacao. Acesso em: 10 dez. 2019.

FERREIRA, E. B.; FONSECA, M. O planejamento das políticas educativas no Brasil e seus desafios atuais. Perspectiva, Florianópolis, v. 29, n. 1, 69-96, jan./jun. 2011. Disponível em: https://www.researchgate.net/publication/315093220_O_planejamen to_das_politicas_educativas_no_Brasil_e_seus_desafios_atuais__doi_1050072175-795X2011v29n1p69. Acesso em: 10 jan. 2020.

INSTITUTO AYRTON SENNA. Relatório anual de resultados de 2012. Disponível em:

https://institutoayrtonsenna.org.br/content/dam/institutoayrtonsen na/documentos/relat\%C3\%B3rios-anuais/Relatorio-Institucional2012.pdf. Acesso em: 06 fev. 2020.

LAGARES, R.; ALMEIDA, G. Q. M.; SANTOS; J. S. Congressos e Conferências Nacionais de educação: espaços sociais democráticos de interlocução e planejamento. Signos, Lajeado, ano 39, n. 1, p. 126-149, 2018. Disponível em:

http://www.univates.br/revistas/index.php/signos/article/viewFile/16 10/1347. Acesso em: 09 jan. 2020.

LINO, Lucília Augusta; MORGAN, Karine Vichiett. Do documento final da Conae ao Plano Nacional de Educação: uma análise da meta 19. RPGE - Revista on line de Política e Gestão Educacional, Araraquara, v. 22, n. esp.1, p. 67-83, mar., 2018. Disponível em: https://periodicos.fclar.unesp.br/rpge/article/view/10784. Acesso em 20 jan. 2020.

LUPORINI, Teresa Jussara; MARTINIAK, Vera Lúcia; MAROCHI, Zélia Maria Lopes. Eleição e formação de diretores de escolas municipais: a legislação e as práticas da rede municipal de ensino de Ponta Grossa. Revista HISTEDBR On-line, Campinas, n.43, p. 214-222, set. 
2011. Disponível em:

http://www.histedbr.fe.unicamp.br/revista/edicoes/43/art15_43.pdf. Acesso em: 10 jan. 2020.

MELLO, Eloisa Helena. Gestão democrática: A participação em Conselho Escolar da cidade de Ponta Grossa. Anais Educere, XII Congresso de Educação 26 a 29 de out. de 2015. Disponível em: https://educere.pucpr.br/p1/anais.html?tipo $=\&$ titulo $=$ \&edicao $=\& a u$ tor=eloisa+helena+mello\&area. Acesso em: 10 jan. 2020.

MELLO, Eloisa Helena. Gestão democrática: escolha de diretores em Ponta Grossa, políticas públicas e participação. Dissertação (Mestrado em Educação) Universidade Tuiuti do Paraná, 2014. $158 f$. Disponível em: https://tede.utp.br/jspui/handle/tede/1631. Acesso em: 10 jan. 2020.

\section{MENEZES, E. T. de; SANTOS, T. H. dos. Verbete Manifesto dos}

Pioneiros da Educação Nova. Dicionário Interativo da Educação Brasileira - Educabrasil. São Paulo: Midiamix, 2001. Disponível em: https://www.educabrasil.com.br/manifesto-dos-pioneiros-daeducacao-nova/. Acesso em: 04 jan. 2020.

PINTO, J. M. R. Federalismo, descentralização e planejamento da educação: desafios aos municípios. Caderno de Pesquisa, São Paulo, v. 44, n. 153, p. 624-644, 2014. Disponível em:

http://www.scielo.br/scielo.php?script=sci_arttext\&pid=S010015742014000300008\&lng=en\&nrm=iso. Acesso em: 11 jan. 2020.

PONTA GROSSA. Secretaria Municipal de Educação. Decreto $\mathbf{n}^{\circ}$ 13.506, de 25 de setembro de 2017. Dispõe sobre a eleição de Diretores das Unidades da Rede Municipal De Ensino. Ponta Grossa 2017. Disponível em: https://leismunicipais.com.br/a1/pr/p/pontagrossa/decreto/2017/1350/13506/decreto-n-13506-2017-dispoesobre-a-eleicao-de-diretores-das-unidades-da-rede-municipal-deensino. Acesso em: 10 jan. 2020.

PONTA GROSSA. Secretaria Municipal de Educação. Decreto $\mathbf{n}^{\circ}$ 590, de 24 de novembro de 2005. Aprova o regulamento das eleições de diretores das escolas da rede municipal de ensino. Disponível em: https://leismunicipais.com.br/a1/pr/p/ponta- 
grossa/decreto/2005/59/590/decreto-n-590-2005-aprova-oregulamento-das-eleicoes-de-diretores-das-escolas-da-redemunicipal-de-ensino. Acesso em: 12 jan. 2020.

PONTA GROSSA. Secretaria Municipal de Educação. Decreto $\mathbf{n}^{\circ}$ 681, de 21 de dezembro de 2001. Regulamento das Eleições de Diretores das Escolas da Rede Municipal de Ensino. Ponta Grossa, 2001. Disponível em http://leismunicipa.is/kmcsh Acesso em: 22 de dez. 2019.

PONTA GROSSA. Secretaria Municipal de Educação. Lei municipal n' 12.213, de 23 de junho de 2015. Institui o Plano Municipal de Educação para o período de 2015 a 2025. Ponta Grossa, 2015. Disponível em: https://leismunicipais.com.br/a1/pr/p/pontagrossa/lei-ordinaria/2015/1222/12213/lei-ordinaria-n-12213-2015institui-o-plano-municipal-de-educacao-para-o-periodo-de-2015-a2025. Acesso em: 08 jan. 2020.

PONTA GROSSA. Secretaria Municipal de Educação. Lei nº 9835, de 30 de dezembro de 2008. Aprova o Plano Municipal de Educação. Ponta Grossa, 2008. Disponível em: https://leismunicipais.com.br/a1/plano-municipal-de-educacaoponta-grossa-pr. Acesso em: 02 jan. 2020.

SABIA, Claudia Pereira de Pádua; ALANIZ, Érika Porceli. Plano Nacional de Educação - PNE (2014-2014): Limites, avanços e perspectivas. Revista do Instituto de Políticas Públicas de Marília, Marília, v.1, n.1, p.35-63, jul./dez. 2015. Disponível em: http://www2.marilia.unesp.br/revistas/index.php/RIPPMAR/article/vi ew/5657. Acesso em: 14 jan. 2020.

SAVIANI, Demerval. Sistema Nacional de Educação e Plano Nacional de Educação: significado, controvérsias e perspectivas. Campinas, SP: Autores Associados, 2014. (Coleção Polêmicas do Nosso Tempo).

SCAFF, Elisangela Alves da Silva. Planejamento da educação e cooperação internacional: uma análise dos programas Monhangara e Fundescola. 2007. 255 f. Tese (Doutorado em 
Educação) - Programa de Pós-Graduação em Educação, Universidade de São Paulo, São Paulo, 2007.

SCAFF, Elisangela Alves da Silva; FONSECA, Marília. (Orgs.). Gestão e planejamento da educação básica nos cenários nacional e internacional. Campinas, SP: Mercado de Letras, 2016.

SCAFF, Elisangela Alves da Silva; OLIVEIRA, Marli dos Santos de.

Planos decenais de educação: sistematização do monitoramento e avaliação nos cenários estadual e municipal Série-Estudos, Campo Grande, MS, v. 23, n. 47, p. 141-162, jan./abr. 2018. Disponível em: http://www.serie-estudos.ucdb.br/index.php/serieestudos/article/view/1081/pdf. Acesso em: 10 jan. 2020.

SCAFF, Elisangela Alves da Silva; OLIVEIRA, Marli dos Santos de; LIMA, Simone Estigarribia de. O planejamento educacional frente às fragilidades da democracia brasileira. ETD- Educação Temática Digital, Campinas, v. 20, n. 4, p. 905-923, out./dez. 2018. Disponível em:

https://periodicos.sbu.unicamp.br/ojs/index.php/etd/article/view/86 49255. Acesso em: 10 jan. 2020.

SOUZA, Ângelo Ricardo de. Meta 19 do PNE - Gestão Democrática. In: OLIVEIRA, J. F.; GOUVEIA, A. B.; ARAÚJO, H. (Orgs.) Caderno de avaliação das metas do Plano Nacional de Educação: PNE 20142024. Brasília: ANPAE, 2018. Disponível em: https://www.anpae.org.br/BibliotecaVirtual/4Publicacoes/CadernoAnlisePNE.pdf. Acesso em: 10 jan. 2020.

SOUZA, Ângelo Ricardo de. Políticas de democratização da gestão educacional no Brasil: experiência e expectativa com o novo plano nacional de educação. Revista Pedagógica, Chapecó, v. 18, n. 39, p. 111-128, set./dez. 2016. Disponível em:

https://bell.unochapeco.edu.br/revistas/index.php/pedagogica/articl e/view/3618. Acesso em: 13 jan. 2020.

Submetido em: Março/ 2020.

Aceito em: Dezembro/ 2020. 